\title{
Return to the resin-modified glass-ionomer cement sandwich technique
}

\author{
W. Liebenberg ${ }^{1}$
}

One of the critical goals of adhesive dentistry is to restore the peripheral seal of dentine that is interrupted when enamel is lost as a result of developmental sequelae, trauma, caries or operative intervention such as preparatory excision. For coronal lesions the exposed strata may be bounded by dentine, enamel or both. Manufacturers continue to work vigorously on resin formulations that will restore this peripheral seal with operative ease and absolute durability.

\section{Enamel bond}

The bond between resin and enamel is generally satisfactory. Most clinicians report that it is possible to achieve seemingly impeccable margins at the visible cavosurfaces when restoring posterior teeth with a direct composite-resin technique. Clinical experience, however, reveals that these resin-tooth interfaces deteriorate as they age. More pertinently, in vitro studies have revealed the formidable challenge of achieving a predictable seal at the proximal margins when tooth-coloured restorations are used. ${ }^{1}$

\section{Dentine bond}

The bond between resin and dentine has been more of a challenge, and numerous generations of resin-bonding agents have been energetically touted as the ultimate dentine bonding agent. Regrettably, predictability of outcome has been trumped by simplicity of application; as a result, the newer bonding agents are certainly simple to use (one bottle; separate etching, priming and rinsing not required) but are no better (in fact, they are far worse) than the 3-bottle systems of the 1990s. For dentine bonding, it appears far easier to achieve a seal than to maintain it, and in vivo studies have confirmed that resin-dentine bonds degrade in the oral cavity. ${ }^{2}$

\section{Enamel protecting dentin}

Several authors have concluded that resin bonded to enamel protects the resin-dentine bond against degradation. ${ }^{3}$ It follows from the data on the bond to enamel and dentine that the reliability of adhesion depends on the peripheral seal to the enamel.

\footnotetext{
'General Dental Practitioner, 201-2609 Westview Dr., North Vancouver, BCV7N4M2, Canada

Correspondence to: Dr William Liebenberg

Email:wliebenb@direct.ca
}

\section{The problem}

For a lesion that is entirely bounded by enamel (ie, an intra-enamel lesion), preserving the dentine seal becomes a matter of establishing a lasting interface between the resin and the enamel. Unfortunately, not all lesions are of this type, and posterior proximal lesions commonly have gingival margins bounded by dentine. The strength and quality of the peripheral seal is therefore compromised and is susceptible to hydrolytic degradation.

\section{The solution}

For a posterior tooth with a proximal margin that extends apical to the cemento-enamel junction and for which a direct toothcoloured restoration is planned, the solution is the open-sandwich technique. This technique is not new, ${ }^{4}$ but it deserves to be revisited, given the commercial proclivity toward simplification and the inability of many of the newer materials to bond reliably and permanently to the diverse and compromised dentine substrates that clinicians encounter in clinical practice. Traditionally, the filler of the 'sandwich' was a glassionomer cement, but resin-modified glassionomer cements (RMGIC) have superior mechanical properties and bonding strength to dentine. ${ }^{5}$ A previous study investigating the durability and cariostatic effect of a modified open-sandwich restoration using an RMGIC concluded that it had acceptable durability for the extensive restorations evaluated. ${ }^{6}$ Furthermore, the open-sandwich technique allows the least amount of microleakage of the various direct restorative options currently available. ${ }^{7}$

\section{The technique}

After removal of the caries and placement of the matrix, the tooth is conditioned with polyacrylic acid according to the manufacturer's directions. A single gingival increment of RMGIC is applied by syringe and is allowed to cure or is subjected to light polymerisation. The restoration is then completed with composite resin.

\section{Lessons to be learned}

The case illustrated here was specifically chosen to demonstrate how the immediate marginal integrity will invariably deteriorate with time. Studies have confirmed that the visible margins have lower leakage scores than those of the proximal gingival margins, which validates the additional effort involved in performing the sandwich technique. Currently available dentine bonding agents can maintain the peripheral seal that is integral to all adhesive procedures only if the seal is bounded by enamel. It is therefore recommended that the sandwich technique be the restoration of choice when proximal gingival margins extend beyond the cementoenamel junction.

1. Brunton PA, Kassir A, Dashti M, Sectos J C. Effect of different application and polymerization techniques on the microleakage of proximal resin composite restorations in vitro. Oper Dent 2004; 29: 54-59.

2. Hashimoto M, Ohno H, Kaga M etal. In vivo degradation of resin-dentin bonds in humans over 1 to 3 years. J Dent Res 2000; 79: 1385-1391.

3. De Munck J, Van Meerbeek B, Yoshida Y etal. Four-year water degradation of total-etch adhesives bonded to dentin. J Dent Res 2003; 82: 136-140.

4. Suzuki M, Jordan R E. Glass ionomer-composite sandwich technique. JAm DentAssoc 1990; 120: 55-57.

5. Pereira L C, Nunes M C, Dibb R G et al. Mechanical properties and bond strength of glass-ionomer cements. J Adhes Dent 2002; 4: 73-80.

6. Andersson-Wenckert I E, van Dijken J W, Kieri C. Durability of extensive Class II open-sandwich restorations with a resin-modified glass ionomer cement after 6 years. Am J Dent 2004; 17: 43-50.

7. Loguerico AD, Alessandra R, Mazzocco K C et al. Microleakage in class II composite resin restorations: total bonding and open sandwich technique. J Adhes Dent 2002; 4: 137-144.

8. Hashimoto M, Sano H, Yoshida E et al. Effects of multiple adhesive coatings on dentin bonding. Oper Dent 2004; 29: 416-423.

This article was originally published with 21 colour figures in the Journal of the Canadian Dental Association (2005; 71: 743-747) and is reproduced here with kind permission from the Editor-in-Chief, Dr John P. O'Keefe. To view the figures see http://www.cda-adc.ca/jcda/vol-71/issue-10/743.htm

Dr Liebenberg will be speaking on Tooth coloured restorations in clinical practice on Friday 19 May 2006 at the 2006 British Dental Conference and Exhibition. It will be held at the International Convention Centre (ICC) in Birmingham on Thursday 18, Friday 19 and Saturday 20 May 2006. 